\title{
Ethiopia and the Refugees: The History, Current Situations and Legal Frameworks
}

\author{
Birhanu Sileshi Watol Desta Tegegne Assefa \\ Wolaita Sodo University, Ethiopia
}

\begin{abstract}
This paper aimed to assess the history and current status of refugees from in Ethiopia. To put into the context of understanding the underlying concepts and assumptions behind refugees and to understand the current status of refugees in Ethiopia, the qualitative research approach is employed. The paper relied on extensively secondary data as a means of collecting relevant and required information. The history of refugees in Ethiopia, Ethiopian legal framework on Refugees and the Current situation of refugees in Ethiopia are the core points assessed through strict textual analysis of the available literature. Moreover, Ethiopia as a host over 166,000 refugees from Somalia (55\%), Eritrea (28\%), and Sudan (15\%), the status of the three corridors of refugee camps i.e. the north camp (Eritrean refugee camps), the east camp (Somali refugee camps) and the west camp (Sudanese refugee camps) discussed in detail.
\end{abstract}

Keywords: Ethiopia, Refugee, legal framework, a refugee camp

DOI: $10.7176 / \mathrm{IAGS} / 71-01$

Publication date: April $30^{\text {th }} 2019$

\section{Introduction}

Ethiopia is the largest country which is situated in the Horn of Africa, and it is the second most populous country in Sub-Saharan Africa. The country is located in northeast Africa bordering Sudan, South Sudan, Kenya, Somalia, Djibouti, and Eritrea. Due to its geographical position, as well as environmental and geo-political developments in the region, Ethiopia is likely to continue to receive asylum seekers from neighboring countries. The country has a history of receiving people displaced by cross-border movements due to droughts, conflicts, political events and civil wars in neighboring countries including Eritrea, Somalia, South Sudan and Sudan. Moreover, the Government of Ethiopia maintains an open-door-policy and has continuously allowed humanitarian access and protection to those seeking refuge on its territory (UNHCR, 2015).

Furthermore, Ethiopia is a State Party to the 1951 Convention relating to the Status of Refugees and its 1967 Protocol as well as to the 1969 OAU Convention governing the Specific Aspects of Refugee Problems in Africa. Similarly, refugee protection is provided within a framework of national laws, notably the Refugee Proclamation of 2004, and the core international human rights treaties that have been ratified by Ethiopia. In 2009, following the voluntary repatriation of South Sudanese refugees, Ethiopia hosted around 90,000 refugees. Again, in 2010 and 2011, with the influx of refugees from Somalia, Sudan and later from South Sudan the number of refugees in Ethiopia increased dramatically. Also, Ethiopia is now the country with the second largest refugee population in Africa. Thus, refugees are sheltered in 25 locations across eight regions of the country. In light of the continued instability and political chaos in the region, it is likely that Ethiopia will remain a major refugee receiving country (UNHCR, 2012).

According to the UNHCR August 2014 report, Ethiopia has overtaken Kenya in having the most number of refugees in Africa with a former count of 629,000 refugees prevalent within all its territories. This toll is estimated to rise above 800,000 by December 2015 , and such exponential growth can be attributed to the various conflicts present in Ethiopia's neighboring regions such as the civil war in Somalia and the political revolt in South Sudan. Eritrea has also contributed to the refugee toll mainly as a consequence of the Eritrean-Ethiopian War. Therefore, Political conflict, war, environmental disasters and conflict on the economic resources occurred in it's neighboring and other East African countries, forced people to cross- a border to Ethiopia. Not only from it's neighboring but also refugees are flooding from Great Lake Regions (Democratic Republic of Congo, Burundi, Uganda, etc.), where there is a continuous civil war target Ethiopia, refugee camps as their destination (EMA, 1999).

Due to its location, Ethiopia cannot escape the aftermath of an instable volatile region prone to conflict and hence continues to receive refugees from neighboring countries. Nowadays, Ethiopia is one of the big refugee hosting nation in the world and the largest refugee-hosting country in Africa accommodating over 650,000 refugees mainly from South Sudan, Somalia, Eritrea and Sudan. Similarly, the government of Ethiopia reaffirms its commitment to continue availing the necessary protection to refugees and is dedicated to the implementation of the internationally set refugee protection and assistance principles and other provisions as per the standards. Ethiopia has also maintained a constructive and cooperative relationship with the rest of its neighbors. Its opendoor policy has made it easy for asylum seekers to access its territory and enjoy the full rights of asylum. The protection of refugees is being implemented in by the provisions put in the refugee proclamation (UNHCR, 
As Ethiopia is the part to the refugee convention and protocols, it provides the host for the large numbers of refugees from its neighboring countries.

\section{Objectives}

While the general objective of this paper is to assess the general situations of refugees in Ethiopia, the specific objectives are:

1. To explore the history of refugees in Ethiopia and its legal framework.

2. To describe the current status of refugees and refugee camps in Ethiopia.

3. To provide some insights for researchers who are interested in refugees at regional and international level.

\section{Methodology}

The study relied on extensively secondary data as a means of collecting relevant and required information. It employed strict textual analysis of the available literature relating to refugees in Ethiopia. The qualitative research approach was utilized in the course of this study. The purpose of this approach was to put into the context of understanding the underlying concepts and assumptions behind refugees, to understand the current status of refugees in Ethiopia.

\section{The History of Refugees in Ethiopia}

"The history of refugee had traced back as long as the history of mankind itself. According to the bible Adam and Eve were driven out of Eden and became thereby the first refugees. Mary and Joseph had to seek refuge in Egypt with the child Jesus Christ. Up through the ages human beings have fled from their homelands to escape the wrath of dictator's conquerors and other oppressors". Just like, refugee influx to Ethiopia is not a recent phenomenon. The history of refugees in Ethiopia had dated back to 615AD when Prophet Mohammed earliest followers with his daughter Rukiya, have sought refuge in Ethiopia and their persecutors arriving from Arabia with assistances and demanded their forcible repatriation, however, King Arma of Axum having interrogated them, turning to the visiting delegation responded in a famous remark. Additionally, since the beginning of the First World War relatively some of refugees from Europe and even Asia have come to live in Ethiopia. Again the African struggle against colonialism was also another factor which drove numerous refugees to Ethiopia (Wondewossen, 1995).

Ethiopia has a long history of hosting refugees in camp settlement and urban center. Moreover, Ethiopia has maintained its ancient civilization of hospitability of its people and the government by granting safety seekers protection and receiving refugee population displaced by war and persecution even at the moments grappling with its economic and developmental difficulties is an expression of its commitment to international standards and humanitarianism. More recently, Ethiopia hosted refugees that are in some cases exceeded one million. These numbers decreased very significantly when most of the Somali refugees repatriated between 1997 and 2005, but many more continued to come (Awoke, 2011).

Moreover, Ethiopia in 2014 took over Kenya as the country with the most refugees in Africa. Through the end of July Ethiopia became host to over 620,000 refugees. Most of these new refugees are from a growing situation in South Sudan. Also, Ethiopia is a major host for Somali and Eritrean refugees who make up the second and third most refugee numbers in the country (Steadman, 2015).

The flows of refugees into Ethiopia are mainly the result of political and civil unrest and frequent natural disasters in the neighboring countries. Although, about 85,000 refugees from several other African countries are present which including Angola, Burundi, Djibouti, Eritrea, Liberia, Rwanda, Somalia, South Africa, Sudan, Uganda, and Yemen. Refugees from Somalia, Sudan, and Eritrea make up the majority. Most recently 3,000 Kenyans sought refuge in Ethiopia. Moreover, Ethiopia hosts some eight refugee camps that are located along its western, northern and eastern parts of the border: two for South Sudanese, four for Eritreans, two for Somali. Accordingly, UNHCR is the main office in charge of the co-ordination of assistance in the various camps. The Administration for Refugee and Returnee Affairs (ARRA), which falls under the National Intelligence and Security Agency, is the national partner of UNHCR. ARRA is in charge of food distribution and security issues in the camps, as well as programming on health and education. To protect its natural resources and infrastructure from the pressure of the refugee influx, Ethiopia has confined the refugees in camps and has limited their rights about movement, education and work opportunities. Permits to leave the camps can be issued for personal, medical, educational or safety reasons (ICMPD, 2008).

For more than 20 years Ethiopia has hosted large numbers of refugees. Currently, Ethiopia is one of the big refugees hosting nation in the world and the largest refugees hosting country in African accommodating over 650,000 refugees mainly from South Sudan, Somali, Eritrea, and Sudan. Although, the government of Ethiopia reaffirms its commitment to continue availing the necessary protection to refugees and is dedicated to the 
implementation of the internally set refugee protection and assistance principles and other provisions as pre the standards. Moreover, historically the government of Ethiopia had an open policy of allowing refugees into Ethiopia and had taken measures to protect their human rights including the recent formal introduction of the out camp policy for qualifying Eritrean refugees. However, refugees are generally regarded as temporary guests and have limited freedom of movement or access to education and employment opportunities (WFP, 2012)

\section{Ethiopian Legal Framework for Refugees}

Ethiopia has expressed its desire to be part of the effort of the international community to protect refugees by signing both the UN and OAU refugee convention. Also, Ethiopia has further shown its concern to protect refugees through its constitution which recognizes certain rights of non-nationals and by adopting a proclamation that specifically deals with refugees. Furthermore, Ethiopia signed the 1951 Geneva Convention relating to the Status of Refugees on 10 Nov 1969 and its 1967 Protocol in Nov 1969. It is a party to the convention with reservations to its article 8 (that obliges states to exempt refugees from measures which may be taken against the person, property or interests of nationals of a foreign State), article 9 (that allows states, in time of war or other grave and exceptional circumstances, to take provisional measures which it considers to be essential to the national security in the case of a particular person, pending a determination by the Contracting State that that person is, in fact, a refugee and that the continuance of such measures is necessary in his case in the interests of national security), article 17(2)( that prohibits states to impose restrictive measures that may be imposed on aliens or the employment of aliens for the protection of the national labour market, to refugees) and article 22(that obliges states to accord to refugees the same treatment as is accorded to nationals with respect to elementary education). In the regional case, Ethiopia is also a party to the 1969 Convention governing the Specific Aspects of Refugee Problems in Africa (African Refugee Convention). Furthermore, Ethiopia is also a party to some international and regional human rights instruments which are meant to protect every individual including refugee (Gizachew, 2009).

Although, Ethiopia is party to the 1951 Refugee Convention and 1967 Protocol and at the regional level Ethiopia is also signatory's to the African union's convention governing the specific aspects of refugee problems in Africa. The 2004 Refugee Proclamation establishes a procedure for applying for asylum and prohibits the government from refusing entry to refugees or asylum seekers and returning them to a country where they would be at risk of persecution. According to the Proclamation, persons can apply for asylum with NISS/ARRA or a police station within 15 days of arrival. However, it authorizes the head of NISS/ARRA to designate classes of persons as prima facie refugees under the African Refugee Convention definition. It requires NISS/ARRA to issue identity cards to refugees and asylum seekers and prohibits prosecution regarding illegal entry or presence. It is clearly stated in the proclamation that, Ethiopia does not allow refugees to work. Thus, the government had only granted work permits to foreigners when there were no qualified nationals available, and rarely issues permit to refugees. However, it has tolerated some refugees with special skills working illegally, as well as refugee participation in the informal sector, including trading in markets or doing other piecemeal jobs. In 2003, Ethiopia signed the Khartoum Declaration of the OAU Ministerial Meeting on Refugees, Returnees and Internally Displaced Persons in Africa. The Declaration calls upon governments to seek durable solutions to the problem of forced population displacement, reaffirms the right of return, appeals to countries of origin to create conditions conductive to voluntary repatriation and recognizes that local integration and resettlement is a desirable solution for dealing with the situation of refugees who are unable to return home(ICMPD,2008).

The Ethiopian refugee proclamation no.409/2004 enacted in July 2004, established the right to asylum and incorporated the provision of the 1951 convention relating to the status of refugees and the 1969 African refugee convention. The Ethiopian refugee proclamation prohibited the government from refusing entry to refugees or asylum seekers or expelling or returning them to any country where they would be at risk of persecution. Furthermore, the Constitution of the Federal Democratic Republic of Ethiopia provided the legal foundation for granting asylum and refugee Protection in Ethiopia. In the case, Article 9(4) provides that, all international agreements ratified by Ethiopia are an integral part of the law of the land. Thus, this provision incorporates all internationally ratified agreements by Ethiopia as part of the national law. Consequently, the 1951 Convention and its 1967 Protocol, the 1969 OAU Convention, the 1984 ACHPR and ICCPR which Ethiopia has ratified contains provisions that address on the various aspects of asylum both from the State and the individual perspectives. The question of asylum and refugee protection in Ethiopia is also regulated by the OAU Convention Governing the Specific Aspect of Refugee Problems in Africa and the 1984 African Charter on human and peoples' rights (ACHPR). Hence, Various international instruments ratified by Ethiopia, notably the 1951 Convention, the OAU Convention, the ACHPR, the UDHR and the ICCPR contains a list of rights guaranteed for asylum seekers and refugees either as a specific vulnerable group or as a member of human kind in general. Therefore, the ratification of these international and regional Conventions ratified by Ethiopia can be invoked as legal protection for asylum seekers and refugees in Ethiopia (Awoke, 2011).

The Ethiopian refugee proclamation of $409 / 2004$ is an expression of Ethiopians humanitarian policy to 
provide hospitability, asylum, and protection assistance to refugees is recognized. Additionally, Ethiopia is a part of the 1951 international refugee convention and its protocol of 1967. At the regional level, it is a part of the OAU refugee convention of 1969. In doing so this, Ethiopia has shown its concern to protect refugees within its territory in line with international convention and agreement.

\section{The Current Situation of Refugees in Ethiopia}

As UNHCR described in its report of October 2003, Ethiopia hosted a total of 128,982 refugees, comprising 28,108 Somali refugees in the East, 94,163 Sudanese refugees in the West, and 6,711 Eritreans in the North and urban areas as well as the refugees from the great lake region (Vaughan, 2004).

It is obvious that the Ethiopian government maintains an open-door policy towards the flood of incoming refugees; however, the practicality of this policy has become questionable as native Ethiopian citizens face not only food and water shortages, but also fear to lose their employment and future job opportunities. As part of the rehabilitation process, refugee camps have been set up in the Ethiopian provinces of Assosa, Dollo Ado, Gambella, Jijiga, Semera, Tigray, Addis Ababa, Afar, and Shire. On the other hand, the EPRDF's effort at providing employment and economic opportunities, physical safeguarding and basic services is notable, given the sheer amount of refugees prevalent. The EPRDF is also supportive of the 1951 Refugee Convention and its 1967 Protocol. An Ethiopian policy that enables refugees who have stayed at the refugee camp for a minimum of 6 months and can demonstrate their ability to sustain themselves without the assistance from the government of Ethiopia or the UNHCR, granted no criminal record, are allowed to leave the camps and reside elsewhere in the country. However, this benefit is currently in favor of only Eritrean or refugee university students (Aggarwall, 2015).

Despite this fact, Ethiopia hosts over 166,000 refugees from Somalia (55\%), Eritrea (28\%), and Sudan $(15 \%)$ as well as from central and eastern Africa (2\%). The largest refugee population in Ethiopia is from Somalia, followed by South Sudan, Eritrea, and Sudan. Also refugees are not only from these countries but also there are close to 6,000 refugees from different countries including Kenya, Djibouti, Democratic Republic of Congo (DRC), Yemen, Burundi, Rwanda, and Uganda. However, as chaos and conflict continued in the state of southern Sudan the number of South Sudanese refugees that have entered into Ethiopia has reached 120,946, that includes 106,743 refugees that have been registered and an estimated 23,000 South Sudanese who have arrived into Ethiopia. Likewise, the asylum seekers continue to arrive in Ethiopia through the Gambella Regional State, mainly through Pagak, Akobo and Burubei border-entry points (UNICEF, 2014).

In July 2014, Ethiopia became the largest refugee-hosting country in Africa due to the influx of Southern Sudanese fleeing conflict since the outbreak of fighting in December 2013. Meanwhile in 2013; more than 115,000 South Sudanese refugees have arrived in Ethiopia. Although, heavy fighting around Nasir in northeastern South Sudan has led to massive displacement with thousands of South Sudanese refugees crossing into Ethiopia. Also, South Sudanese continue to arrive at a daily average of 211 individuals. At the same time, they entered Ethiopia through the Pagak, Akobo, Burbiey and Raad entry points. This brings the total number of South Sudanese refugees in Ethiopia from 15 December 2013 to 219,009, including 215,331 in Gambella and 3,678 individuals in the Benishangul-Gumuz region, near Assosa the western Ethiopia. This brings the total number of South Sudanese refugees in Ethiopia to 282,429 including 63,420 who were in the country before December 2013. The total number of South Sudanese refugees who have entered Ethiopia and crossed the border into the Gambella region since the outbreak of the conflict in mid-December 2013, stands at 215,331 individuals. Generally, the focus of the Gambella operation was to come up with contingency plans given continuing new arrivals and the development of the newly allocated site for the establishment of the refugee camp Pugnido two(UNHCR,2015).

Historically, Somali refugees have been begining to come or present in Ethiopia since the late 1980s, with major influxes occurring in 1991 following the collapse of the Said Barre regime and the flow in fighting in 1994, bringing the total number of Somali refugees in Ethiopia to 628,000 during the mid-1990s. In the main time following relative peace in north western Somalia in 1997, over 205,300 Somalis were repatriated in several phases by 2002, while thousands of others either spontaneously repatriated or stayed among the local Somali community in Ethiopia. However, following the escalation of conflict and instability in south-central Somalia, the influx of Somali refugees resumed and continued to flow, and four new camps had to be opened over the past four years. Likewise, there are 91,201 Somali refugees in Ethiopia, accounting for 55\% of the total refugee population in the country and reside in five different camps: Aw-barre, Kebribeyah and Sheder camps in the Jijiga area in Eastern Ethiopia, as well as in Bokolmanyo and Melkadida camps in the Dolo Ado area in south eastern Ethiopia. At the same time, Eritrean refugee has also entered Ethiopia following the Ethio-Eritrean border conflict between 1998 and 2000. Initially, they were just over 4,000 refugees settled in Wala'nhibi and were later moved to Shimelba camp in May 2004. Currently, there are a total of 46,256 Eritrean refugees in Ethiopia, accounting for $28 \%$ of the overall refugee population in the country and they reside in three camps in the Tigray region: Shimelba, Mai-Aini and AdiHarush and in settlements or amongst the host community in the 
Afar region in Berhale, Asayita and other villages in the northern Ethiopia (WFP, UNHCR, 2010).

Ethiopia takes resettlement as the only practical, durable solution in the operational process, as instability and persecution continued in the countries of origin such as (Sudan, South Sudan, DRC, Eritrea and Somalia) effectively precluding voluntary repatriation, while local integration remains vague. Ethiopia's resettlement referral target for 2015 is 5,965 individuals (UNHCR, 2015).

As Ethiopia is signing the refugee convention and protocol as well as the African refugee convention, it gives host for refugees for the settlement. Therefore, refugees are getting to the Ethiopian border and settled in the different camps in a different direction of the country. As a usual, the pushing factor for the refugees in the neighboring countries and other states are war, natural disasters, civil war and others. Consequently, when they arrived into Ethiopian borders do to these factories they get relief in Ethiopia because of even the hospitability behavior of the Ethiopian communities.

\section{i. $\quad$ Eritrean Refugee camp (Northern camp)}

The Eritrean refugees began to enter into Ethiopia following the Ethio-Eritrean border conflict between 1998 and 2000. They were initially just over 4,000 refugees settled in Wala'nhibi and were later moved to Shimelba camp in May 2004. There are currently a total of 46,256 Eritrean refugees in Ethiopia, accounting for $28 \%$ of the overall refugee population in the country and they reside in three camps in the Tigray region: Shimelba, MaiAini and AdiHarush and in settlements or amongst the host community in the Afar region in Berhale, Asayita and other villages (Samuel, 2014).

\section{Shimelba Camp}

The camp was established in May 2004 and at the time hosts 8,907 refugees, 34\% of whom are females and 66\% are males. The camp comprises of two main ethnic groups, the Tigrinia speaking, who account for $56 \%$ of the camp population and are mainly young single males of urban backgrounds wishing to resettle to a third country, and $42 \%$ of which are Kunamas who are agrarian families, and the remaining $2 \%$ are from Saho, Bilen, Tigre and Nara ethnic groups. About $77 \%$ of the camp is comprised of single households. In 2015 the Shimelba refugee camp hosted 5,421 the Eritrean refugee (UNICEF, 2015).

\section{Mai-Aini Camp}

The Mai-Aini camp was established in May 2008 and hosts 11,971 refugees, $71 \%$ of whom are male, and $29 \%$ of whom are female. The camp previously hosted over 17,000 refugees until the revalidation exercise in May 2010 , when the figure reduced to 11,000 people. Although the resettlement programme has not yet begun in the camp, the significant reduction in the camp population can be attributed to the illegal movement of refugees within Ethiopia, Sudan and other neighboring countries. But in 2015 the total numbers of refugee hosts in the Mai-Aini are 10,898 Eritreans. Additionally, Adi-Harush hosts 8,492 Eritrean refugees in 2015(USCRI, 2015).

\section{Somali Refugee camps (Eastern camps) Somali Refugees in Dolo Ado}

The majority of Somali refugees in this area belong to the Marehan, Rahan-weyn, Hawiye, Dir, Darod, Ogaden, Sherkhal, Asharaf clans followed by the Midgan/Gaboye clan. Homogeneity in clan composition, religion, language and culture among the refugees has made their acceptance and continued refuge in Ethiopia and the local community relatively easy. The majority of the refugee population in this area is of rural origin with a pastoralist economic base. There are currently no obvious population-wide durable solutions. The possibility of voluntary repatriation is not a viable option at this stage for the Somali caseload given the ongoing insecurity at home. Local integration is not available either. Resettlement to a third country remains the only genuine, durable solution but is not a population-wide solution given the small numbers of refugees accepted for resettlement each year. The numbers of refugee hosted in the camp were 37,423 (Melaku, 2012).

\section{Bokolmanyo Camp}

Bokolmanyo camp was established in 2009 and hosts 21,586 refugees, $54 \%$ of whom are female, and $46 \%$ of whom are male. New arrivals have consistently arrived in Bokolmanyo, with major influxes during September to December 2009 and an average of 70 people per month in 2010, which were primarily cases of family reunification, since new arrivals are now taken to Melkadida camp. The camp has been in an emergency response mode for the last year, addressing the need for life-saving and essential services. Despite the continuing influx, it is important for the population that has been in the camp for a longer period that programming and policy reflect a more comprehensive package of services that move beyond life-saving into life-enhancing and asset building. Therefore the numbers of refugee hosts in 2015 in this camp are 42,436. Moreover, Malkadid was opened in 2010 and 2015 shelter some 44,910 refugees. Kobe was also opened in 2011 and 2015 shelter 42,533 refugees. Similarly, Hilawene was opened in 2011 and 2015 hosts 42,549 (UNICEF, 2015).

\section{Sudanese Refugee camps (Western camps)}

Most of the Sudanese refugees arrived in Ethiopia in the early 1980s. New arrivals continue to flow into the country due to continued conflict in their country. A large number of refugees have crossed into the western 
most Gambella region of Ethiopia since the start of the conflict in 2013 in neighboring South Sudan. The refugees arrive in dire condition and are mostly concentrated at border points with limited assistance before being relocated to camps. This influx is stretching the local capacity with several camps being occupied. Currently, refugees have been relocated to Pugnido, Tierkidi, Jewi, Kule, and Okugo which have capacity for 216, 604 camps are being set up in Gambella (UNHCR, 2016).

Pugnido is the oldest refugee camp in the Gambella Region of Western Ethiopia and is hosting refugees that arrived twenty years ago since 1993 and those who arrived within recent months and since 18 Nov 2014; some 16,183 refugees relocated from different entry points arrived in Pugnido of which 14,746 have been fully registered. The camp population comprised of refugees from South and Northern Sudanese in 2015 are 62,830 . Also,Tierkidi camp currently hosts 52,240 Sudanese refugees. The Jewi camp is currently being develop ped site planning and road construction have started, and it is hosts 46,491. Moreover, Kule and Okugo camps are currently hosts 47,478 and 7,565 refugees respectively (UNHCR, 2015).

The other one is Sherkole refugee camp which is located $50 \mathrm{~km}$ from the Ethio- Sudan's border, which was opened by UNHCR in 1997 in response to an influx of Southern Sudanese refugees fleeing conflict in Blue Nile and Upper Nile States of Sudan. Yet, during the Sudanese war, the population consisted of mainly ethnic groups Maban, Uduk and Funj people, but in 2005 they were joined by another refugees almost 3000 new refugees from Eritrea and the Great lakes region in expectation of a repatriation of Sudanese refugees that began in 2006. However, the camp overlooks ravines and foothills in a semiarid area which supports the construction of traditional mud and grass roof or mud-brick buildings. Moreover, refugees maintained backyard gardens to supplement food rations. Thus, UNHCR investment in infrastructure and facilities as well as market opportunities has also led to increased settlement of host indigenous population around the camp (Stewart, 2013)

It is clear that since 1997, Sherkole refugee camp has been began to hosting Sudanese refugees. Nevertheless, between 2006 and 2008 following voluntary repatriation, the numbers of refugees in the camp was reduced from 16,000 to nearly 4,000. Afterwards on 2 September 2011, an influx of Sudanese refugees came to the region as a result of fighting between the Sudan Armed Forces (SAF) and members of the Sudan People's Liberation movement-North (SPLM-N) in Blue Nile state of Sudan (IFRC, 2012).

Furthermore, the beginning of the fighting between government forces and freedom fighters of the SPLM$\mathrm{N}$ in Sudan have driven 34,500 refugees into Ethiopia since September 2011, in addition to nearly 4,000 refugees who stayed in Sherkole camp before the outbreak of the conflict in Blue Nile. However, with the influx of large numbers of refugees, they are accommodated in the three camps; Sherkole, Tongo and Bambasi in Benishangule-Gumuze region in the western Ethiopia. But as the numbers of refugees are increased highly in the Sherkole camp, the new camp, Bambasi and Tongo were opened in June 2012 following relocation of nearly 10,500 refugees from Ad Damazine temporary transit Centre which has recently been closed by the Government of Ethiopia. Here the new camp Bambasi specifically can host up to 20,000 people. Unlike Ad-Damazin, Bambasi is located at a safe distance from the Ethiopia-Sudan border and has sufficient water sources. Some 4,000 refugees opted out of the relocation process but a few hundred have moved spontaneously to the new camp in August. Moreover, approximately 2,000 individuals, along with an estimated 8,000 livestock, are reported to be living amongst the local community according to local officials. These refugees opted out of the relocation because of a lack of grazing land in Bambasi (UNHCR, 2012).

Since 15 September, 2011 some 2,700 refugees have been voluntarily moved to Sherkole camp in Benishangul Gumuz region of western Ethiopia. Therefore, a number of the Sudanese refugees have expressed their interest in relocation to the camp and also most of the refugees are prefer to stay at the Sherkole camp because of the availability of food, water and shelter as they are among the most immediate needs of the refugee population in the camp (UN, 2011).

In general in Ethiopian's neighboring state, Blue Nile, a fighting between the Sudanese Armed Forces and members of the Sudanese People's Liberation Movement (North) broke out in September 2011. As a result of this event the two western Ethiopian camps has been accommodating more than 26,000 Sudanese refugees Fugnido in Gambella region and Sherkole in the BenishangulGumuz region and the unstable situation between Sudan Armed force and the Sudanese Liberation movement currently forcing thousands of Sudanese to seek security in western Ethiopia in Sherkole camp(UNHCR, 2014).

Therefore, in the current time there are figuratively 11,508 numbers of refugees are living in the sherkole refugee camp. The largest numbers of the Sherkole camp refugees are from Sudan, South Sudan and Congo and other African countries respectively. The number consists of both male and female. But the refugees from the other African countries are small in numbers. However, the number from Sudan are 6083, South Sudan 4723, Congolese 607, Burundi 42, Cameroon,1 cote dlvoire 2, Liberia 4, Uganda 14,Tanzania 2, Eritrea 3 and there are 27 female Ethiopian refugees in living in Sherkole refugee camp. There are also different ethnic groups of refugees living in Sherkole camp. These are Maban 3133, Funju 3949, Dinka 1028, Uduk 1170, Nuyer 228 and others are 2000 living in the camp (ARRA, 2016). 


\section{References}

Aggarwall V.2015. Human rights council, measures to aid refugees in Ethiopia. Dhirub Ambani international model united nations $20^{\text {th }}$ November- $23^{\text {rd }}$ November. research report.

ARRA. 2016. Administration for Refugees returnee Affairs, Assosa, Ethiopia.

Awoke D.2011.The right to Asylum; A case study with particular reference to Somali and Eritrean Asylumseekers and refugees in Ethiopia. M.A thesis Addis Ababa University School of graduate studies Faculty of law.

EMA. 1999. Assessment of refugee impact on the natural environment of southern and south Western Ethiopia, Addis Ababa,Ethiopia.

Gizachew A.2009. Refugee law teaching material, sponsored by the justice and legal system research institutions.Chilot.wordpress.com,unpublished material.

ICMPD. 2008. East African migration Route initiative Gaps and Needs Analysis project Country Reports; Ethiopia, Kenya and Libya.Printed in Austria.

IFRC.2012. MDRET011-Ethiopian-population movement. Emergency appeal operation update. Ethiopia

Melaku B.2012. Squeac Report Dollo Ado Refugee camp.Coverage monitoring Network.

Samuel H.2014. Living out of camp: Alternative to camp-based Assistance for Eritrean Refugees in Ethiopia.Commissioned by NRC.

Steadman C.2015. Rights of refugees, the internally displaced and Asylum seeking people. old dominion University, model united nations society.

Stewart BT.,Checchi F., Palmer JJ., Grundy C.2013. Validity and feasibility of a satellite imagery-based method for rapid estimation of displaced population. London school of hygiene and topical medicine.

UNHCR. 2015. UNHCR Fact sheet-Ethiopia.

UNHCR.2012. UNHCR Ethiopia. Ethiopia refugee.update July-August 2012.

UNHCR.2012. Sherkole profile.Assoas filed office, Assoas, Ethiopia.

UNHCR.2012. UNHCR Ethiopia. Ethiopia refugee update July-August 2012.

UNHCR.2014. Hosting refugees in Ethiopia.UNHCR fact sheet-Ethiopia.

UNHCR.2014. Hosting refugees in Ethiopia.UNHCR fact sheet-Ethiopia.

UNHCR.2015. Pugndio Camp profile. Camp phase: care and maintenance August 2015.

UNHCR.2015. UNHCR Ethiopia; south Sudan situation operational update. Ethiopia.

UNHCR.2016. South Sudan Situation UNHCR Regional up date 86 4-6 March, 2016.

UNICEF. 2014. Ethiopian humanitarian situation report. UNCIEF Ethiopia situation report.

UNICEF.2015. Ethiopia Humanitarian situation Report. SiteRep1-reporting period January- February 2015

USCRI. 2015. Forgotten refugees: Eritrean Children in Northern Ethiopia. Findings recommendations. United state committee for refugee report.

Vaugham S. 2004. Ethiopia; a situation analysis and Trend Assessment.commissioned by the united nation higher commission for refugees protection (DIP). Written on human rights, forced migration and political conflict,uk. unpublished.

WFP,UNHCR,ARRA.2010. Ethiopian Joint assessment mission. Ethiopian joint assessment mission 2010, the assessment by UNHCR, ARRA and WFP.

WFP.2012. Summary, report of the joint UNHCR, WFP impact evaluation on the contribution of food Assistance to durable solution in protected refugee situation- Ethiopia. Executive Board first regular session. Rome.

Wondewossen L. 1995. The Ethiopian Refugee law and place of women in it. RSP Documentation center. Unpublished. 